$\frac{19}{1 / 3 / 19}$

DR. 291

MLM-2659

\title{
Gas Phase Thermal Diffusion of Stable Isotopes
}

\author{
Charles F. Eck
}

\section{MASTER}

November 1, 1979

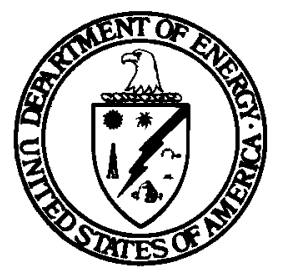

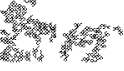
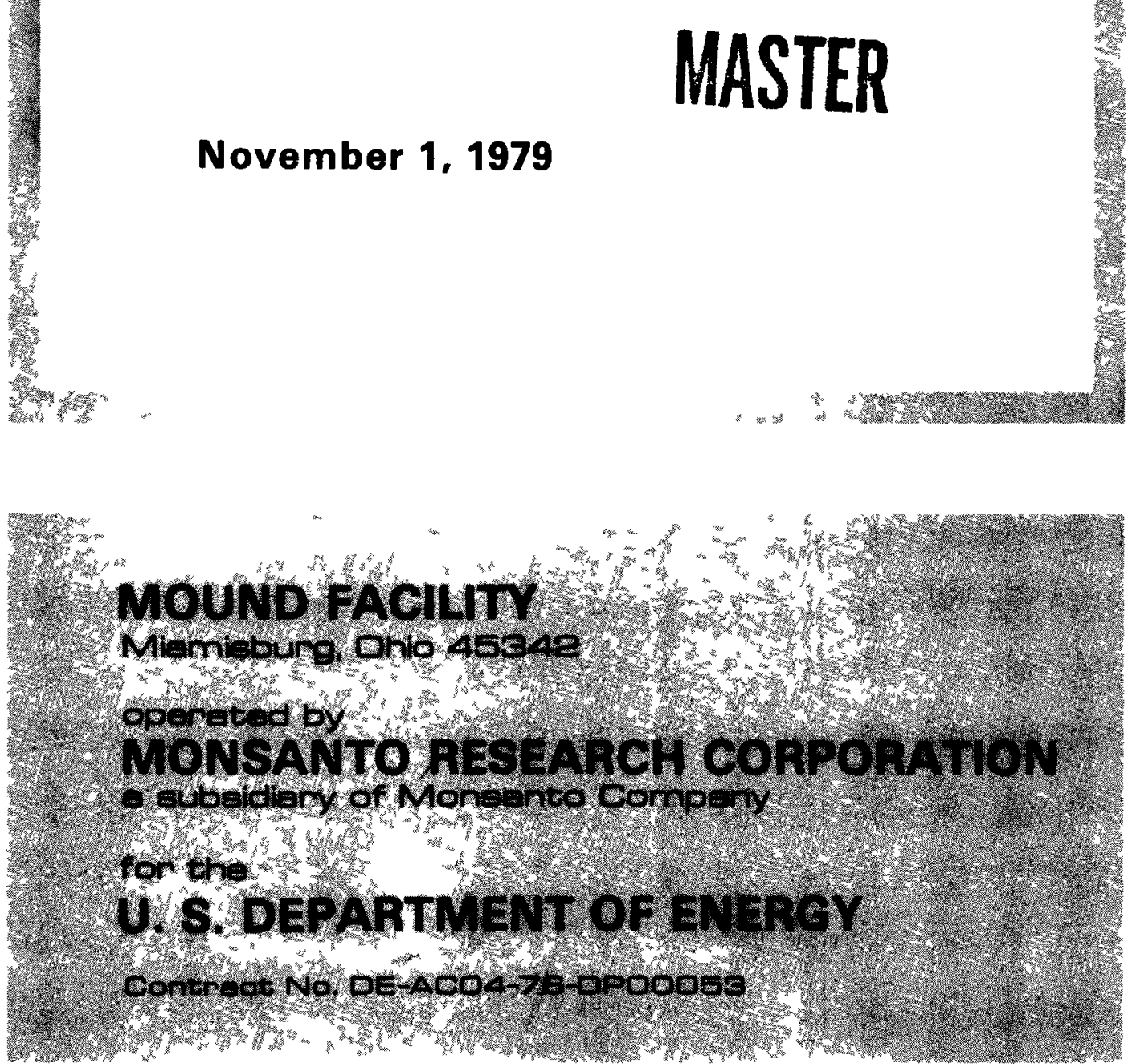


\section{NOTICE}

This report was prepared as an account of work sponsored by an agency of the United States Government. Neither the United States nor any agency thereof, nor any of their employees, makes any warranty, expressed or implied, or assumes any legal liability or responsibility for any third party's use or the results of such use of any information, apparatus, product or process dis. closed in this report, or represents that its use by such third party would not infringe privately owned rights.

Printed in the United States of America Available from

National Technical Information Service U. S. Department of Commerce 5285 Port Royal Road Springfield, VA 22161

NTIS price codes

Printed copy: $\mathrm{AO} 2$

Microfiche copy: A01 


\section{DISCLAIMER}

This report was prepared as an account of work sponsored by an agency of the United States Government. Neither the United States Government nor any agency Thereof, nor any of their employees, makes any warranty, express or implied, or assumes any legal liability or responsibility for the accuracy, completeness, or usefulness of any information, apparatus, product, or process disclosed, or represents that its use would not infringe privately owned rights. Reference herein to any specific commercial product, process, or service by trade name, trademark, manufacturer, or otherwise does not necessarily constitute or imply its endorsement, recommendation, or favoring by the United States Government or any agency thereof. The views and opinions of authors expressed herein do not necessarily state or reflect those of the United States Government or any agency thereof. 


\section{DISCLAIMER}

Portions of this document may be illegible in electronic image products. Images are produced from the best available original document. 


\section{Gas Phase Thermal Diffusion of Stable Isotopes}

Charles F. Eck*

Issued: November 1, 1979

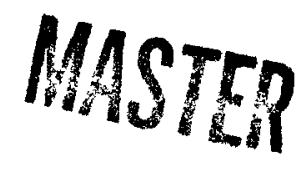

*Former Leader, Stable Isotopes, at Mound Facility

MOUND FACILITY

Miamisburg, Ohio 45342

operated by

MONSANTO RESEARCH CORPORATION

a subsidiary of Monsanto Company

for the

\section{U. S. DEPARTMENT OF ENERGY}

Contract No. DE-ACO4-76-DPODO53 


\section{Contents}

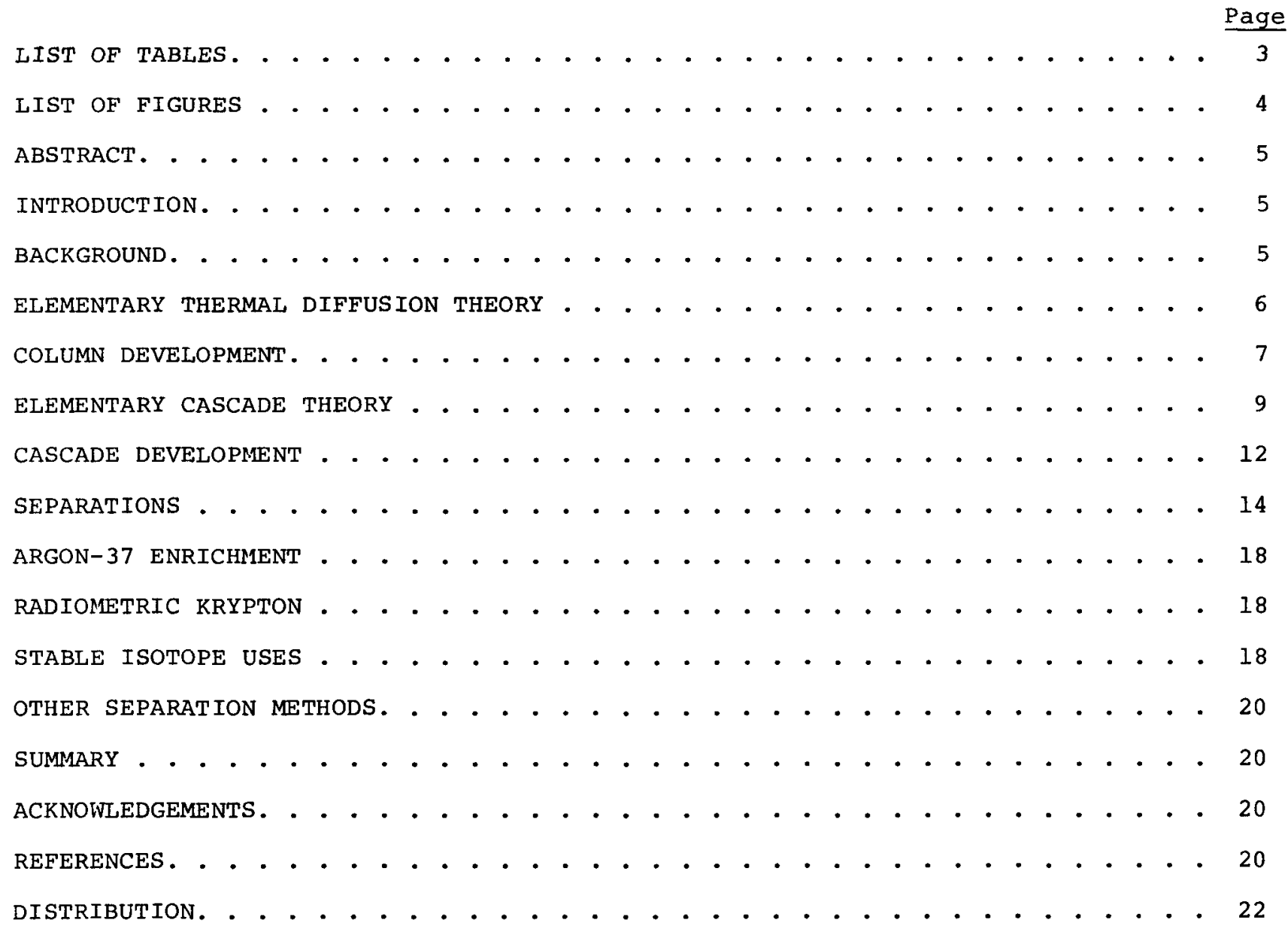




\section{List of tables}

Table $\quad$ Page

I PARAMETERS OF THERMAL DIFFUSION COLUMNS. . . . . . . . . . . . 10

2 ENRICHED END ISOTOPES. . . . . . . . . . . . . . . . . . . 16

3 ENRICHED MIDDLE ISOTOPES . . . . . . . . . . . . . . . . 16

4 SHIPMENTS OF ENRICHED STABLE ISOTOPES

FROM MOUND FACILITY. . . . . . . . . . . . . . . . . . 17 


\section{List of figures}

Figure Page

1 HOT WIRE THERMAL DIFFUSION COLUMN. . . . . . . . . . . . . . . . . . . . 7

2 ALIGNING FINGER FOR THE HOT WIRE IN A THERMAL

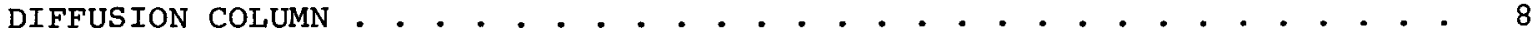

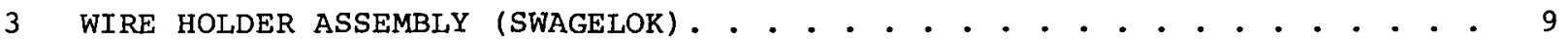

4 CONCENTRIC TUBE THERMAL DIFFUSION COLUMN

5 CASCADE CONFIGURATIONS FOR PRODUCING CARBON-13 . • • . . . . . . . . . . 11

6 SWING UNIT FOR INTERSTAGE CIRCULATION IN A THERMAL DIFFUSION CASCADE. . . . . . . . . . . . . . . . . . . . . . . . . 13

7 XENON-124 CASCADE PROCESS FLOWSHEET. . . . . . . . . . . . . . . . . . 15

8 SYSTEM AND CASCADE CONFIGURATION FOR THE SEPARATION OF KRYPTON-82 • . . . . . . . . . . . . . . . . • . . . . . . 15 


\section{Abstract}

The separation of stable isotopes at Mound Facility is reviewed from a historical perspective. The historical development of thermal diffusion from a laboratory process to a separation facility that handles all the noble gases is described. In addition, elementary thermal diffusion theory and elementary cascade theory are presented along with a brief review of the uses of stable isotopes.

\section{Introduction}

The United States Atomic Energy Commission (AEC) had been separating isotopes of the elements and distributing them at cost to research and development workers in federal, university, and commercial laboratories throughout the free world from the 1940's until 1975. When the Energy Research and Development Administration was formed from the AEC in 1975*, the new organization assumed support for this work. The AEC's program of isotope separation for peacetime use was the historic development of electromagnetic separation of radioactive and stable isotopes at Oak Ridge National Laboratory [1], and the development of gas phase thermal diffusion facilities at Mound Facility (formerly Mound Laboratory). Both locations have demonstrated the usefulness of these methods and have supplied a wide variety of stable isotopes to meet the research needs of many scientists.

At Mound Facility, thermal diffusion work has been developed to such a high degree that most of the stable isotopes of the unique noble gases have been separated at significantly high enrichments. These

* In 1977, Mound Facility became part of the newly formed Department of Energy (DOE). isotopes have been distributed worldwide. This report describes the historical development of thermal diffusion from a laboratory process to a separation facility that handles all the noble gases.

\section{Background}

The Atomic Energy Commission had always been involved in isotope separation. After World War II, some of the AEC's electromagnetic facilities (Calutrons) were converted from weapon material application to isotope separation for peacetime use [2]. By the 1950's, there was a need to supply enriched gaseous stable isotopes for research and development in government and university laboratories. Gaseous isotopes were separated very inefficiently by the electromagnetic method because of the difficulty in collecting the separated gaseous products. Consequently, methods of separating isotopes in the gaseous state became of interest. In 1938, Clusius and Dickel [3] devised a thermogravitational column which used the thermal diffusion effect between hot and cold surfaces to achieve significant isotope separation. They demonstrated its usefulness by separating isotopes of many elements.

During World War II, a thermal diffusion plant was built at Oak Ridge, Tennessee for the separation of uranium isotopes in the liquid phase [4]. This plant provided 
a primary enrichment to reduce the quantity of feed material required for the Calutron plant.

In 1954 and the years following, several pilot columns were started up at Mound Facility (formerly Mound Laboratory) to study gas phase separation of hydrogen and helium isotopes [5]. Applications were rapidly extended to other noble gases, primarily krypton and xenon. Since that time, the AEC/ERDA/DOE isotope separation facility has grown to over 150 thermal diffusion columns and separates stable isotopes of all the noble gases and carbon-13. This includes enriching a given isotope to a very high level, so that other isotopes are present only in the low parts per million range, as well as separating isotopes from multicomponent feeds. To date, Mound Facility has separated thousands of liters of noble gas stable isotopes.

\section{Elementary thermal diffusion theory}

Thermal diffusion is a second order effect, and theory essentially states that a temperature gradient in a twocomponent system should also result in a concentration gradient. This was predicted by Champman and Enskog in the 1910's and was demonstrated in a simple twobulb experiment. However, until clusius and Dickel [3] invented the thermogravitational column, this effect was of interest primarily to physical scientists in the study of gas molecule interaction and was of no practical use for isotope separation.

In a thermal diffusion column, the center wire or tube is kept at a high temperature; and the outside wall of the column is cooled. The temperature difference between the hot center wire and cold outside wall developes a radial concentration gradient. Also, the cooler gases at the cold wall fall; and the warmer gases at the hot wall rise to produce a thermal convection effect of countercurrent gas flows at the two walls. These two effects allow a column system of reasonable length to separate isotopes at high concentrations. For simplicity, separation of a binary mixture will be discussed. The flow rate of one component to the end of a column is given by the expression:

$$
\begin{aligned}
\tau_{A} & ={ } w_{A P} \\
& =H w_{A}\left(1-w_{A}\right)-\left(K_{C}+K_{d}\right) \frac{d w_{A}}{d z}+P w_{A},
\end{aligned}
$$

where $\tau_{A}$ is the transport or flow rate of component $A ; P$ is the net flow rate along the column or product withdrawal in mass per unit time; $w_{A}$ is the weight fraction of component $\mathrm{A} ; \mathrm{w}_{\mathrm{AP}}$ is the weight fraction at the product end; and $z$ is the distance along the column. This equation shows 1) the thermal diffusion separation effect represented by $\mathrm{H}$, the column transport coefficient, and 2) the remixing effect from convective remixing by $\mathrm{K}_{\mathrm{C}}$, the column convective coefficient, and diffusion remixing by $\mathrm{K}_{\mathrm{d}}$, the column diffusion remixing coefficient. These column coefficients are functions of column dimensions, operating conditions, and gas properties.

At column equilibrium, where there is no net flow rate nor component flow, the transport equation is simplified to the following form:

$$
q=e^{H L / K} \text {. }
$$


where $\mathrm{q}$ is the separation factor, $\mathrm{K}=$ $K_{c}+K_{d}$, and $L$ is the lenqth of the column. The separation factor of the column, $q$, is defined by:

$$
q=\frac{\left(w_{A} / w_{B}\right)^{T}}{\left(w_{A} / w_{B}\right)^{B}}=\left\{\frac{w_{A} /\left(1-w_{A}\right)}{\left\{W_{A} /\left(1-w_{A}\right)\right.}\right\} \text { T }
$$

Subscripts $A$ and $B$ refer to the two binary components whereas $T$ and $B$ refer to the top and bottom of the column, respectively. Thus, column coefficient ratios can readily be determined from equilibrium experiments. To determine the specific column coefficients, flow rate experiments must be run [6]. For equilibrium column conditions, the separation factor reaches a distinct maximum at a specific pressure in a given column. This pressure depends on the gas between the hot and cold walls. For continuous Elow operation in separating quantities of an isotope, an efficient pressure has been determined to be 1.7 times the pressure at which maximum separation is obtained under equilibrium conditions. This higher pressure allows higher product flow rates than those at the equilibrium optimum pressure and thus compensates for the reduced separation factor to provide increased separative work. In addition, a considerable amount of work has been performed on verification of the basic thermal diffusion theory [7].

\section{Column development}

The initial columns at Mound Facility for isotope separations and for evaluation studies were simple in design. The thermal diffusion column consisted primarily of a hot wire suspended axially in a vertical cylindrical stainless steel tube. The hot wire was heated with electrical current, and the tube was cooled externally with water. Direct current from a motor-generator set provided steady power to the top of the center wire. To complete the electrical circuit and allow for thermal expansion of the wire, a tungsten weight suspended from the bottom end of the wire contacted a mercury pool in the bottom of the column, (as shown in Figure 1). To maintain good vertical alignment of the column, the column was mounted on a rigid aluminum I-beam and hung from a swivel and closely aligned with an adjustable bottom bracket. The hot wire had to be well centered to obtain a good separation effect since experiments showed that small misalignment caused large decreases in separation efficiency. The wire centering method

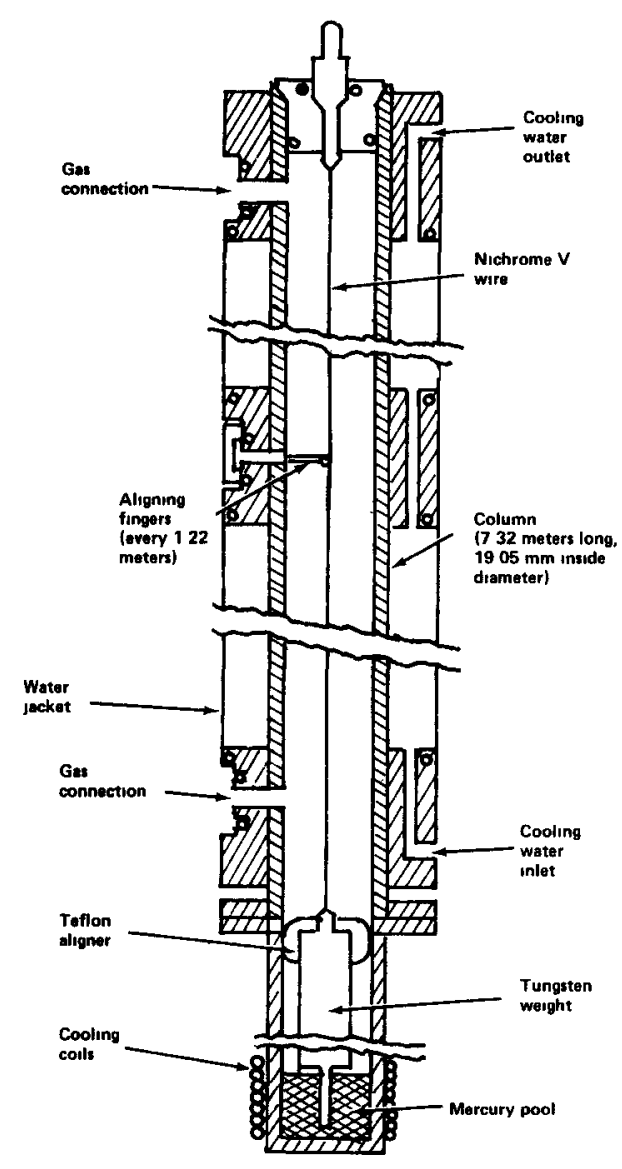

FIGURE 1 - Hot wire thermal diffusion Column. 
passed through several designs. Basically, a nozzle was provided at intervals in the cylindrical tube; and a finger was inserted into the nozzle and held the wire centered. The original finger was an assembly of piano wire on a brass rod insulated by a glass tube and held in place by o-rings and a nut. To overcome the difficulty of hooking the wire by feel, another nozzle was installed at right angles to each original one. With a glass disc in this nozzle, visual guidance for hooking and aligning the center wire greatly eased this work. The latest finger had a short Teflon rod with a shoulder at the outer end. The shoulder was dimensioned to center the hooks and was held in place by a flange. The wire hook was replaced by a machined metal hook. Figure 2 shows the aligning finger.

The wire suspension method also evolved through several stages. Initially, the bent end of the center wire was held in a steel chuck by the electrical stud that screwed into the chuck. Changes for improvement of the electrical contact and vertical alignment of the center wire to prevent arcing and burnout resulted in using a Swagelok union (its body screws into the stud). Then the nut with the center wire and two ferrules screws into the other end of the union body as shown in Figure 3, which compresses the fitting to make a good contact with the wire.

As noted earlier, good axial alignment of the center wire was essential. This was achieved by stretching the wire slightly prior to use to remove kinks and any residual bends. Originally, the wire was stretched by hand before installation in the column. As longer columns with smaller end clearances were developed, it necessitated stretching the wire in place after installation in the column. A ratchet system was devised for this purpose.

Initially, molybdenum was used for the center wires and was quite satisfactory for gas mixtures containing no oxygen; however, as investigations increased and

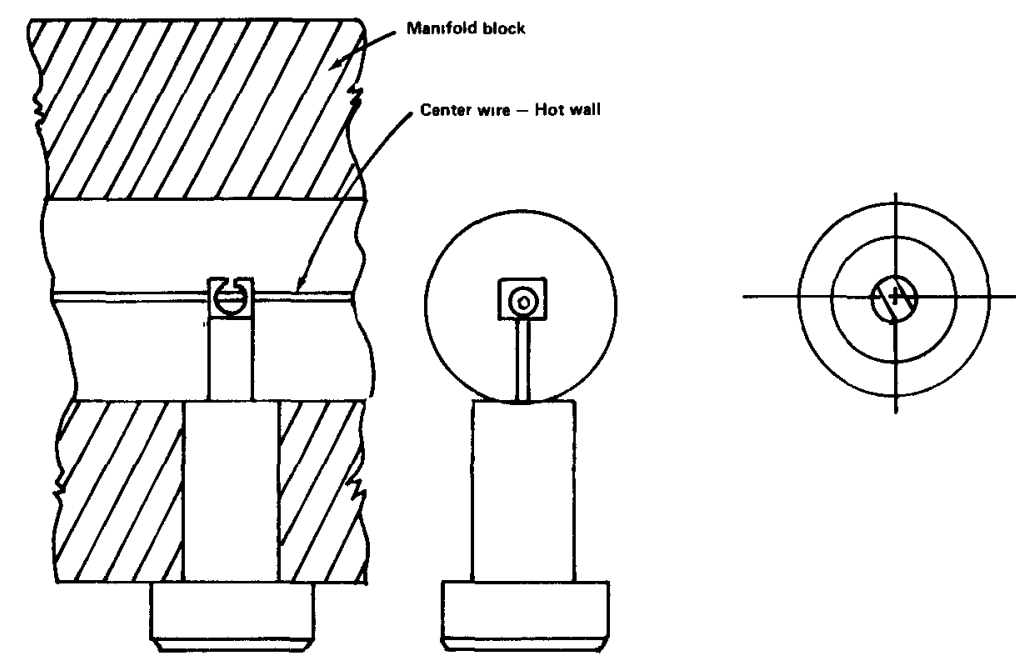

Alignıng Finger

FIGURE 2 - Aligning finger for the hot wire in a thermal diffusion column. 


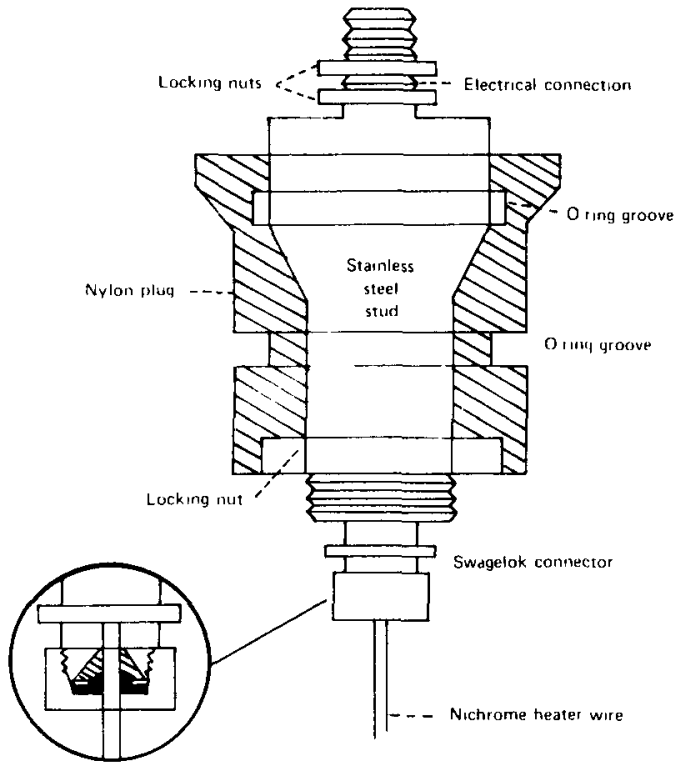

FIGURE 3 - Wire holder assembly (Swagelok).

oxygen was tested, molybdenum wires oxidized at normal operating temperatures of $900^{\circ} \mathrm{C}$ or above. Nichrome $V^{*}$ showed no oxidation at these temperatures and is now generally used as the center wire material.

Since the separation achievable by a 7.32-meter column was not adequate for many separation problems, the cascading of columns became necessary. Hot-wire columns of the construction described above required considerable space since each column was mounted on an individual I-beam. For large cascade systems and improved separations, a concentric tubetype column was developed. This type was designed to allow a number of columns

ॠA product of International Nickel: $80 \% \mathrm{Ni}, 20 \% \mathrm{Cr}$. to be cooled in one water jacket [8]. The hot wall was formed by a tubular heater, powered by alternating current. The electrical return was the sheath of the heater. The column itself was simply constructed. It was a copper tube with gas side connections at the top and bottom. The gas connections and the heater passed through the top flange as shown in Figure 4. This arrangement allowed 19 columns to be installed in one water jacket. The heaters were centered by installing thrcepronged sleeves at intervals along the heater. The size of the thermal diffusion columns used are given in Table 1 .

\section{Elementary cascade theory}

For production of isotopes at high enrichments and at rates on the order of liters per year, a single thermal diffusion column is generally not adequate. Therefore, it usually is necessary to group a number of columns in a series-parallel arrangement known as a cascade.

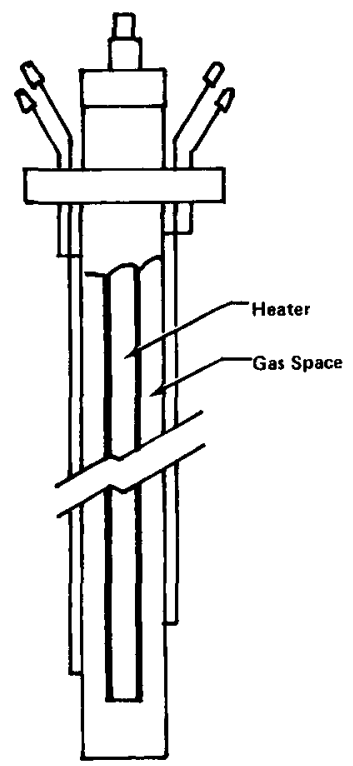

FIGURE 4 - Concentric tube thermal diffusion column. 
Type

Length (cm)

Cold Wall Diameter (cm)

Hot Wall Diameter (cm)

Cold Wall Temperature $\left({ }^{\circ} \mathrm{C}\right)$

Hot Wall Temperature $\left({ }^{\circ} \mathrm{C}\right)$
Hot Wire

731.5

1.906

0.159

15

800
Concentric Tube

488 and 366

1.44

0.8

15

750
The "shape" of a cascade, that is the details of the arrangement of the columns, is a problem of fundamental importance in isotope separation. This problem arose on a large scale for the first time during World War II, because of the need for large quantities of deuterium oxide (heavy water) and uranium-235. One of the results to emerge from the Manhattan Project was the concept of the ideal cascade. The shape of the ideal cascade is described by the two following equations:

$$
\begin{aligned}
& \frac{H}{\mathrm{P}}=2 \frac{\mathrm{N}_{\mathrm{P}}-\mathrm{N}}{\mathrm{n}(\mathrm{l}-\mathrm{N})} \\
& \frac{\mathrm{N}}{\mathrm{I}-\mathrm{N}}=\frac{\mathrm{N}_{\mathrm{O}}}{I-\mathrm{N}_{\mathrm{O}}} \mathrm{e}^{\frac{1}{2} \mathrm{y}},
\end{aligned}
$$

where $\mathrm{N}=$ mol fraction of the desired isotope,

$N_{p}=$ mol fraction of the desired isotope in the product stream,

$\mathrm{N}_{\mathrm{O}}=$ mol fraction of the desired isotope at the feed point,

$P=$ product rate,

$\mathrm{H}=$ thermal diffusion column parameter characteristic of isotope transport, and

$\mathrm{y}=$ dimensionless length parameter.

The first equation defines the "width" of the cascade, that is the number of columns in parallel, as a function of the mol fraction of the desired isotope; the second equation predicts the variation of mol fraction as a function of location along the length coordinate of the cascade. By combining Equations 1 and 2, it is possible to describe the width of the ideal cascade as a function of location along the cascade.

The ideal cascade is a concept that is limited to binary or quasibinary isotopic mixtures. For the case of multicomponent isotopic mixtures (for example, krypton or xenon), the ideal cascade equations cannot be directly applied; although these equations can be of some value in designing systems to enrich the various isotopes. They cannot, however, specify unique, optimum systems for multicomponent separations. Design of acceptable systems requires considerable judgement and art. The ideal cascades have some important properties. Of all possible cascades that produce $\mathrm{P}$ mols of product with a mol fraction $\mathrm{N}_{\mathrm{p}}$, starting from feed material of mol fraction $\mathrm{N}_{\mathrm{O}}$, the ideal cascade minimizes the number of separating elements (that is, columns) that are required to achieve the desired production. This implies a minimum capital investment. Secondly, internal flows of process material are also minimized, which corresponds to minimization of operating costs. Thirdly, the ideal cascade has a tapered shape, that is, it is wide at the feed 
point and narrow at the product end. Tapering leads to minimization of material holdup (that is, content) of the system and to minimum start-up time.

The following example illustrates the advantage of a tapered versus an untapered cascade. In Figure 5, a schematic representation of two such cascades for production of $90 \%$ carbon-13 methane is shown. The columns that comprise the two cascades are all identical in design. The important point is that the tapered cascade is composed of 20 columns, whereas the untapered cascade is composed of 65 columns. Furthermore, the holdup of methane amounts to $28 \mathrm{~g}$ in the tapered cascade whereas it amounts to $93 \mathrm{~g}$ in the untapered cascade. With the carbon isotope concentrations at the feed points fixed at the natural abundance value, the calculated production rate for the tapered cascade was $0.175 \mathrm{~g} /$ day of 908 carbon-13 methane; collection of product began 20 days after start-up. For the untapered cascade the production rate was $0.203 \mathrm{~g} /$ day of carbon-13 methane; collection of product began 100 days after start-up. Clearly, the untapered cascade is a poor choice for this case.

The cascade section where the desired isotope is concentrated is referred to as the enricher; the other cascade section is called the stripper. The material exiting from the enricher contains relatively more of the desired isotope than the feed material, whereas that emerging from the stripper contains relatively less. By making the stripper longer, more of the desired isotope can be recovered from the feed materials. If feed material is plentiful and cheap, there is little incentive to recover a large portion of the desired isotope contained in the feed. On the other hand, if the feed material is scarce and/or expensive, there may be a very great incentive to recover a high proportion of the desired isotope from the feed. The decision as to whether or not to use a stripper, and if so, how large $a$ one, is answered by comparing the

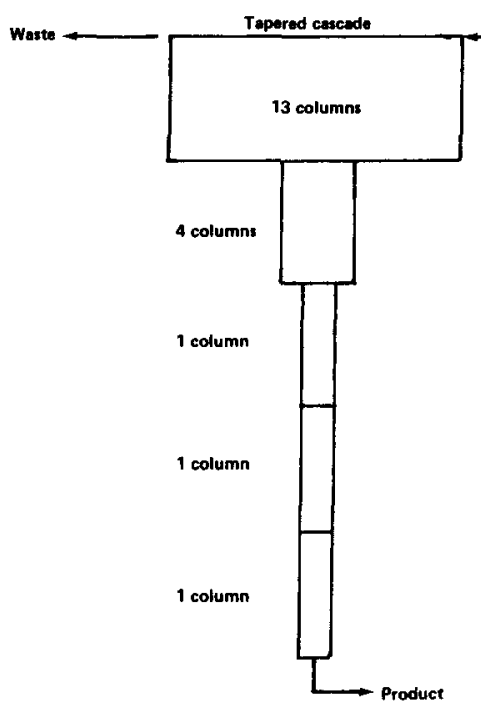

Total number of columns $=\mathbf{2 0}$

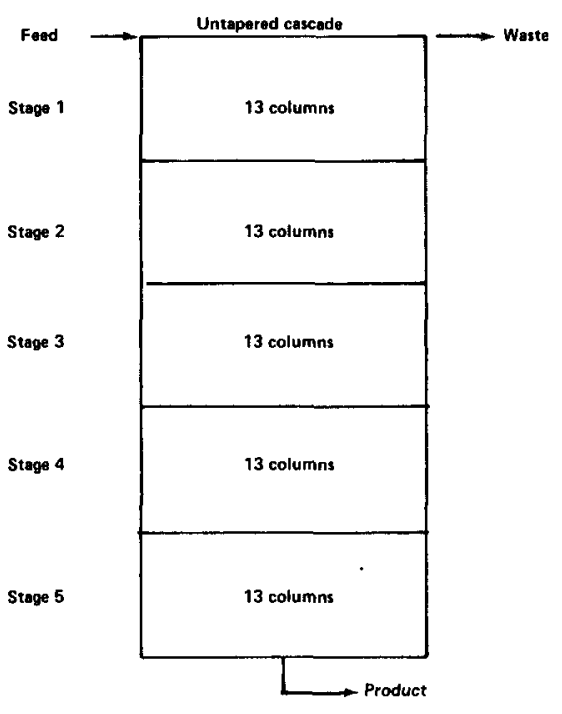

Total number of columns $=65$

FIGURE 5 - Cascade configurations for producing carbon-13. 
value of the additional product material to the cost of building and operating the stripper.

\section{Cascade development}

Cascades normally are made up of many individual separation units, such as a thermal diffusion column. In order for such systems to function efficiently, the partially separated gas streams from each unit must be transported to the next stage without retrograde mixing or other disturbances. In thermal diffusion systems, the gas at the top of a stage should be very nearly equal in composition to the gas at the bottom of the next higher stage. To approach this equality, the gas from the top of one stage is circulated to the bottom of the next stage and then returns in a closed loop to its starting point.

One of the early methods used was connecting the two stages together with a thermal circulating loop; that is, two lines connected the bottom of one stage with the top of the next stage, and one of these lines was heated, which caused an upward convection effect; and the return was through the other unheated line. Experiments on this method indicated lack of capacity needed for column gas interchange in thermal diffusion cascades.

The thermal convection pump idea was replaced with peristaltic pumps. These pumps had many metal fingers that compressed a plastic tube successively so that gas was squeezed ahead of the fingers and forced forward. The tubing sustained wear from the compression and had to be moved periodically to expose a new section to the fingers. If this were not done soon enough, the tubing would split and valuable separated gas would be lost.

Another pumping method that was tried for this application was a Toepler pump*. Instead of the usual glass type used in the laboratory, a stainless steel one was built that required a frit permeable to gas but not mercury - several materials were tried. For this purpose, a glass frit, protected by a Fluorothene 15- $\mathrm{mm}$ frit and a perforated stainless steel disc in a Unichrome molded unit, performed satisfactorily most of the time; but greater reliability was needed for continuously operating systems.

A pump needing less attention was a micro bellows pump. This pump consisted of a small metal bellows with check valves at the inlet and outlet, and a motor-driven cam activated the bellows. However, an occasional failure of the bellows caused gas loss.

Another method of interstage mixing was the swing method [9]. This method was used successfully in a five-stage system with the swing unit (shown in Figure 6) at the product end. The compressor pumped a given volume of gas into the column with the solenoid valve closed. When the compressor stopped, the solenoid valve opened; and the column gas bled back to the product tank. This allowed sufficient transport through the system. When a sixth stage was added, the interstage circulation was insufficient to provide adequate transport between the feed reservoir and the first

* A gas pump invented by a German physicist in which the alternate raising and lowering of a column of mercury causes a vacuum and exhausts the gas through another tube. 


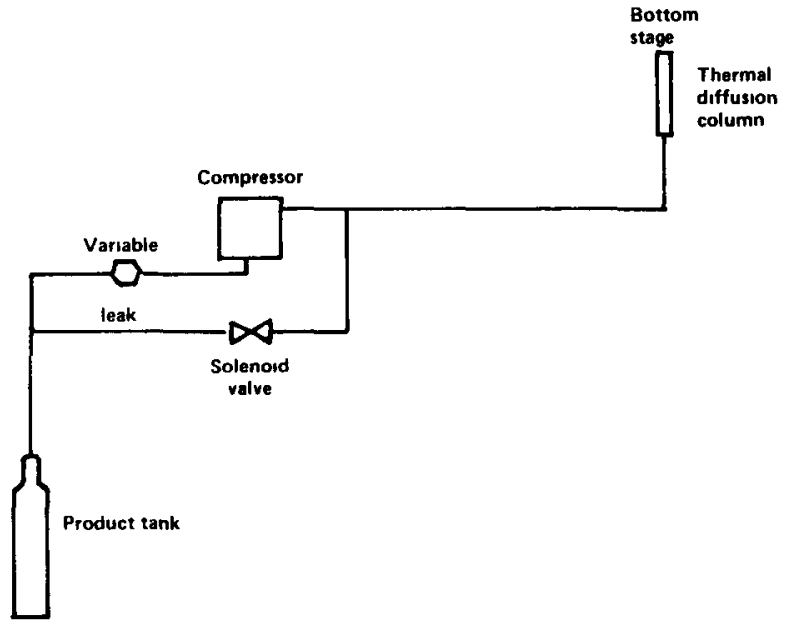

FIGURE 6 - Swing unit for interstage circulation in a thermal diffusion cascade.

stage. A swing unit, similar to the one at the product end, was installed at the feed end; and the deficiency was corrected.

Several sealed pumps have been used successfully. The simplest and most inexpensive type was the hermetically sealed compressor normally used in a household refrigerator. This was suitable for cascades in which a large holdup gas volume had little effect, and traces of compressor oil could be tolerated. Some systems, in which the isotope being separated was present in small quantities, required pumps of very small holdup volume. Several special pumps were developed for these systems. Two of them were a canned circulating pump and a magneticallydriven circulating pump [8] . The magnetically-ariven pump has proven to be the most reliable and is being used on practically all the cascades.

Besides interstage circulation, product and depleted stream flow controls were needed in all flows leaving the cascade systems. The only exception was a system having reservoirs at the feed and product ends, which was a batch type of operation. In this case, the column gas was circulated through a purification trap, and if necessary, the reservoir tank, and back to the column. The gas flows in noble gas isotope separation systems were usually very small. In many cases, simple controls included a needle valve leading to a product tank that was maintained within a small pressure range. The pressure rise in the tank indicated the product flow rate. Periodically the gas would be removed so that the flow rate would not be affected significantly. Another control method for small flows used a variable leak with a compressor downstream discharging into a product tank.

For larger flows, double-solenoid valves with a volume chamber between them were used. Initially, an adjustable volume chamber was built in which an o-ring sealed plunger allowed the volume to be set at will for the flow required. With a timed cam circuit, the first solenoid valve fed the gas in, then closed; and the second solenoid valve would open to allow the gas to flow into a compressor for subsequent pumping into a product tank. It turned out that it was simpler to vary the frequency of solenoid valves on the timers than to adjust to the volume setting for a specific flow. Later, fixed volumes were used between the double solenoid valves.

A large cascade usually has a number of columns in one stage; and in an ideal system, the temperatures of the hot walls would be identical for all the columns in one stage. In practice, there are small temperature differences that seriously 
reduce the separation in the individual columns. To avoid this occurrence, solenoid valves are located in each of the bottom lines of a column. Stepping switches are set to time the solenoid valves so that no two columns are open to the bottom manifold at one time, thus preventing any adverse circulation.

\section{Separations}

The amount of separation or enrichment of an isotope in a thermal diffusion column depends upon the isotopes being separated, the column geometry or parameters, and column operating conditions. As noted earlier, usually a number of columns are used in a cascaded system and arranged in series and parallel configuration; columns in series make a longer cascade and provide a higher separation, and columns in parallel make a wider cascade and provide greater throughput. Most of the separations at Mound Facility used at least two stages. Each separation system had a unique cascade configuration to produce the quantity and enrichment required for a given isotope. Individual systems varied from 2 to 24 columns each -2 to 8 stages long and 1 to 14 columns wide.

of the noble gas isotopes, xenon isotopes were the most difficult to separate because of their high molecular weight and their numerousness. Natural xenon contains the following isotopes:

\begin{tabular}{ccccc} 
Isotope & Mol 8 & & Isotope & Mol 8 \\
\cline { 1 - 1 } Xenon-124 & 0.096 & & Xenon-131 & 21.18 \\
Xenon-126 & 0.090 & Xenon-132 & 26.89 \\
Xenon-128 & 1.92 & Xenon-134 & 10.44 \\
Xenon-129 & 26.44 & Xenon-136 & 8.87 \\
Xenon-130 & 4.08 & &
\end{tabular}

Although xenon-124 was an end isotope and required only the removal of isotopes heavier than itself, it was a difficult isotope to separate because of its large mass and the small mass difference from its next stable isotope. Initially, a severely tapered cascade produced a batch of $40 \%$ xenon-124. Chanqing to a narrow square cascade and reduced pressure resulted in making a batch enriched to $65 \%$, which is the highest that this isotope has been enriched. On a continuous flow basis, this isotope was enriched to $20 \%$ in a concentric tube column cascade having a 14-3-1-1-1 configuration as shown in Figure 7 .

Neon has three isotopes: neon-20,90.58 abundance; neon-21, 0.278; neon-22, 9.238 . Neon-21, the middle isotope, has been separated in several ways. Initially, an intermediate stream was removed from the point of an internal peak of neon-2l in a four-stage cascade system. This stream was processed several times to remove additional amounts of the end isotopes, neon-20 and neon-22. A second method used an auxiliary gas, deuterated methane, to space itself on each side of the neon21 in a cascade profile and, thus, separate the neon-21 to a high degree [10]. Another scheme used two cascades; the first one separated a binary isotope product containing essentially neon-21 and neon-22, and the second cascade separated the neon-2l at a high enrichment [10].

Elements with numerous isotopes, such as krypton, required several cascades to enrich its middle isotopes. One arrangement that was used specifically for enriching krypton-82, shown in Figure 8 , needed three cascades to sufficiently deplete the product of the lighter and heavier isotopes. When the middle isotopes 


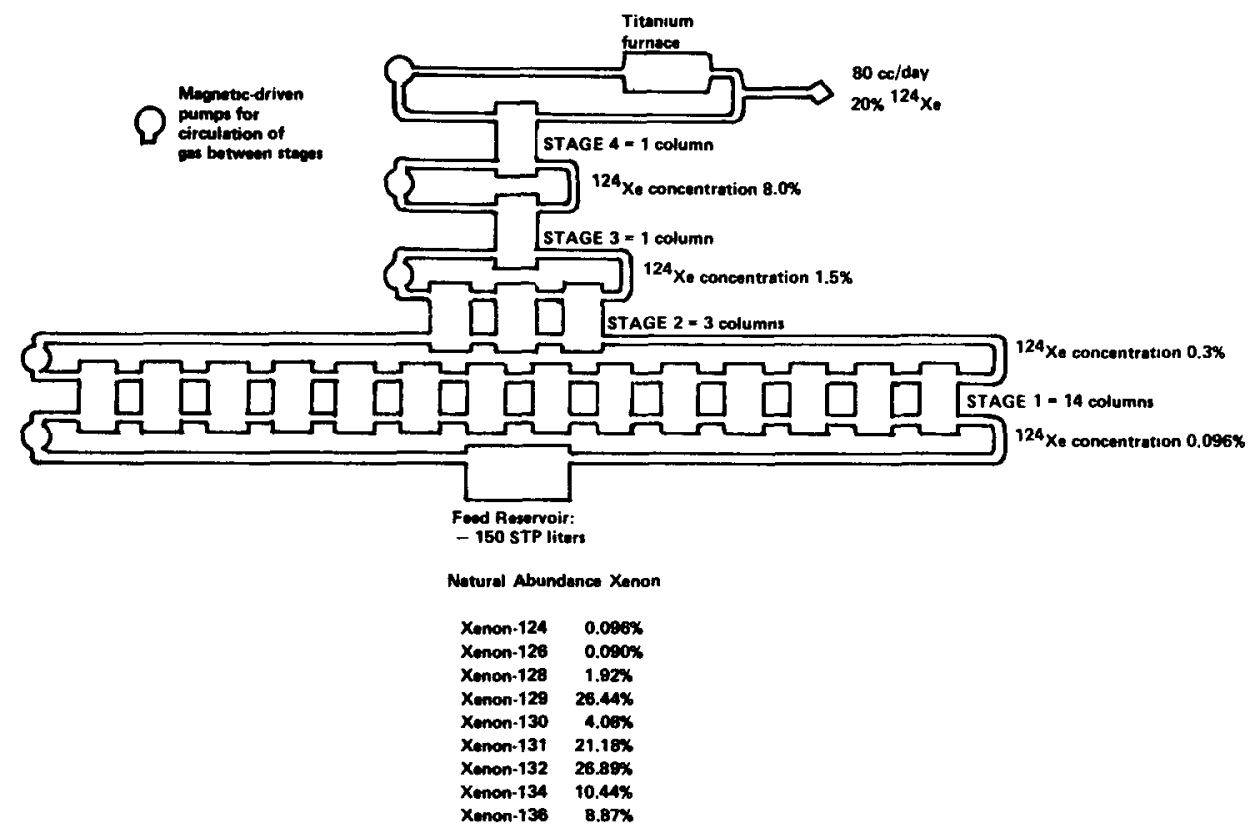

FIGURE 7 - Xenon-124 cascade process flowsheet.

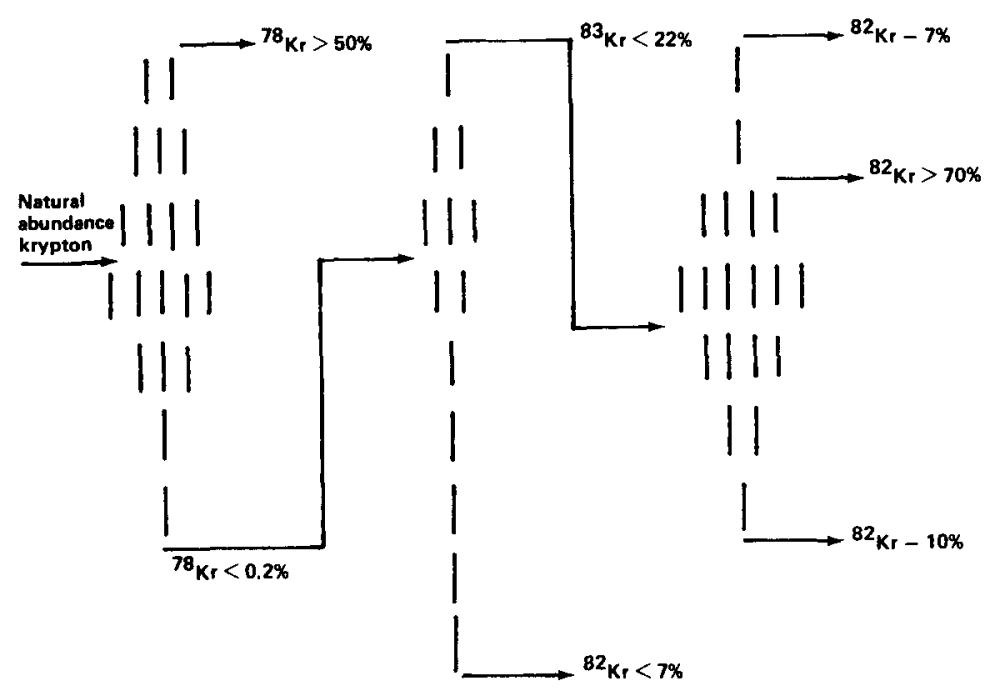

FIGURE 8 - System and cascade configuration for the separation of krypton-82. 
of xenon are needed, similar cascade arrangements could be designed and used.

Carbon-13 had been on the market for many years at an enrichment of $60 \%$. A cyanide exchange process and distillation of carbon monoxide were used for this enrichment. Realizing the potential value of high enrichment carbon-13 in quantity, the AEC encouraged its development. Consequently, Mound Facility became involved in the investigation of thermal diffusion separation of carbon. isotopes. Problems were encountered with carbon-13 that were not encountered with the other isotopes. Noble gases are monoatomic and stable, but many gaseous carbon compounds are inherently thermally unstable. A study of several compounds showed that methane had the best separation factor. However, it decomposed at the usual hot-wall temperature of $800^{\circ} \mathrm{C}$ and required a reduced temperature of $450^{\circ} \mathrm{C}$. An assortment of hot-wire and concentric tube columns in a cascade configuration of 2-2-1-1-1-1-1-1-1 enriched natural abundance methane from 1.1 to $90 \%$ carbon-13 [11]. Production was small, and the need greater. Then carbon monoxide distillation and carbon dioxidecarbamate chemical exchange were used. Subsequently, Los Alamos Scientific Laboratory developed a large-scale carbon monoxide distillation system for 908 carbon-13 [11]. The heavy isotopes of oxygen caused the carbon enrichment to be limited when separated by distillation. Methane made from the enriched carbon monoxide provided a very suitable feed for a thermal diffusion cascade, which has enriched carbon-13 to 978 and 998 .

Stable isotopes enriched at Mound Facility are shown in Tables 2 and 3 . Product concentrations of 998 or higher are shown in
Table 2. These are the end isotopes of elements having 2 to 9 isotopes. The only noble gas end isotope not enriched to this level is xenon-124. Its highest enrichment was $65 \%$. High cost and lack of demand have discouraged development of methods to enrich this isotope to a higher level. Intermediate or middle isotopes that have been enriched significantly are shown in Table 3. The isotopes shown in these tables have been shipped to 41 states and 32 foreign countries in all populated continents. Annual quantities of these shipments are shown in Table 4 .

Table 2 - ENRICHED END ISOTOPES

\begin{tabular}{|c|c|c|}
\hline & \multicolumn{2}{|c|}{ Concentration (mol 8 ) } \\
\hline Isotope & Feed & Product \\
\hline Heli um-3 & 1 & 99.99958 \\
\hline Neon-20 & $90.5 \quad \mathrm{a}$ & 99 \\
\hline Neon-22 & $9.23^{\mathrm{a}}$ & 99 \\
\hline Argon -36 & $0.337^{\mathrm{a}}$ & 99.5 \\
\hline Argon-40 & $99.6 \quad \mathrm{a}$ & 99.999 \\
\hline Krypton-78 & $0.35^{\mathrm{a}}$ & 99 \\
\hline Krypton-86 & $17.37^{\mathrm{a}}$ & 99 \\
\hline Xenon-136 & 40 & 99 \\
\hline Carbon -13 & 90 & 99 \\
\hline
\end{tabular}

\begin{tabular}{|lccc|} 
Table 3 - ENRICHED MIDDLE & ISOTOPES \\
Isotope & & \multicolumn{2}{c|}{ Concentration (mo18) } \\
\cline { 3 - 4 } Neon-21 & & 0.27 & Product \\
Argon-38 & & 0.063 & 90 \\
Krypton-80 & 2.27 & 95 \\
Krypton-82 & 11.56 & 70 \\
Krypton-83 & 11.55 & 70 \\
Krypton-84 & 56.9 & 70 \\
Xenon-126 & 0.090 & 90 \\
Xenon-129 & 26.44 & 10 \\
Xenon-131 & 11 & 60 \\
\hline
\end{tabular}




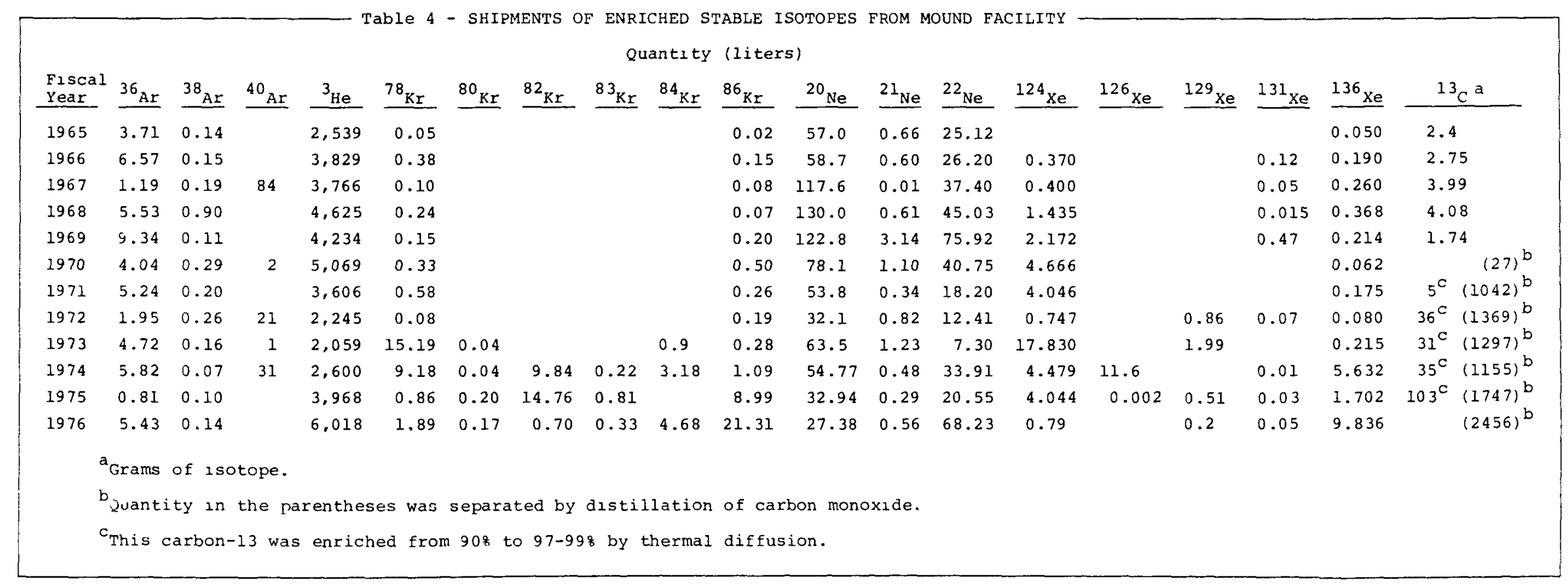




\section{Argon-37-enrichment}

In recent years, interest had developed in studies of atmospheric mixing processes. one method that had proved helpful in this work was the measurement of cosmic -rayproduced argon-37 in the troposphere [12]. Argon-37 is radioactive and has a halflife of only 35 days. Since the existing argon-37 levels were too low to measure, an enrichment cascade was required that would provide the desired quantitative separation and still allow time for final purification and counting for valid data. A hot-wire, 7-1-1-1-1, thermal diffusion cascade erriched this isotope a factor of 70-fold in 6 days.

\section{Radiometric krypton}

Some natural materials used by scientists are contaminated by radioactivity. Such materials are unsuitable for use in lowlevel experiments. An example of such a material is krypton. Several years ago, a laboratory required krypton with a krypton-85 level equivalent to the natural level prior to World War II. No more natural sources were available. All krypton produced by air separation plants prior to the war had been used. Using the experience gained from the enrichment of stable isotopes, a thermal diffusion cascade was built to fill this need. Reservoir systems for feed and product were used in a square cascade having a 3-3-33-3-3 configuration. As the separation progressed in this system, the concentrations of krypton-84 and krypton-86 were measured periodically at the top of the cascade. Simulated computer data were then used to estimate the concentration of krypton-85. The level of krypton-85 in the final product was reduced to less than $1 \times 10^{-14}$ mol 8 , which proved suitable for the experimental work.

\section{Stable isotope uses}

Enriched isotopes are widely used in many disciplines as well as in specific applications. The most obvious use is in the study of nuclear properties, forces, and structure. Chemistry uses these materials in kinetic and structural studies. Other uses are in agriculture, biology, geology, and medicine. More than 130 domestic universities and over 100 foreign universities have used these enriched isotopes in research. In many studies, stable isotopes are more satisfactory for isotope dilution or tracer methods than radioactive isotopes. Applications using unique properties will be mentioned.

Helium-3 became widely used in the early 1960 's when a 10-fold price reduction took place. Being the most fugacious gas known, it is particularly useful in low temperature studies and as a cryogenic refrigerant. With a normal boiling point of $3.2 \mathrm{~K}$, it can be used for further cooling by simply pumping on it to attain temperatures down to $0.5 \mathrm{~K}$. A dilution-type refrigerator using helium- 3 and helium-4 and the effect from phase change has been developed so that temperatures in the millidegree range can be maintained [13]. Another large use is in the nuclear field of neutron detection and spectrometry. Bombardment of helium-3 with neutrons forms tritium, which can be readily detected with a counter. No excited products are produced, only clean, noncorrosive, tritium and a proton. An interesting application is the logging of oil wells for petroleum studies [14]. Laser research has shown that a helium-3/ neon-20 laser has improved properties, such as power and gain, over a natural helium neon laser.

One of the problems in breeder reactors, which are being considered to relieve some 
of the expected energy shortage, is to locate a fuel element that has developed a leak. Early location of the leaky element is important to avoid environmental impact and to reduce downtime in replacing the defective element, thus saving cost and power. Argonne National Laboratory developed an isotope tracer method for the EBR-II fast breeder reactor. This method involved injecting a specific volume of xenon-124, xenon126, xenon-128, and xenon-129 in a unique ratio into the fuel element. Later, should this fuel element leak during operation, the gas leaks into the reactor cover gas and is recovered. A mass spectrometer analysis of the recovered gas indicates which element is leaking and needs replacement. The Fast Flux Test Facility at Hanford will use unique ratios of krypton and xenon stable isotopes [15].

Another specific and valuable use of stable isotopes is in the manufacture of radiopharmaceuticals. Helium, krypton, and xenon isotopes have been used for this purpose [16]. Bombardment of oxygen16 with helium-3 produces fluorine-18, which is used in bone scanning. Krypton84 on proton bombardment produces rubidium84, used in myocardium scanning. Xenon124 is used considerably for making iodine125 by neutron irradiation. The latter isotope is used in thyroid function tests and as a portable x-ray unit.

Noble gas isotopes have found uses in measurement standards [17]. Helium-3 has an exceptionally high vapor pressure at low temperatures $(0.5 \mathrm{~K})$ compared to other gases, which accordingly makes it most suitable for the present vapor pressure standard temperature scale at such temperatures. One of the fixed points on the International Practical Temperature Scale is $27.402 \mathrm{~K}$, which is the boiling point of natural neon. Natural neon is a ternary mixture of stable isotopes. To avoid discrepancies from isotopic variations, the use of highly enriched neon-20 has been suggested for this purpose. In addition, study of the meter standard has revealed that krypton-86 is the preferred isotope for this use. Consequently, a multiple of the wavelength of its orange light at $63 \mathrm{~K}$ has been used as the international standard for the length of the meter. This allows a laboratory to set up the standard for its own use.

An interesting study using an isotope dilution technique is the application of argon-38 for dating meteorites and other minerals by determining the amount of radiogenic argon -40 , which is the decay product of potassium-40. Argon-36 and argon-38 tracers are injected into the gas sample from the mineral. An analysis provides data on various argon isotope ratios so that the radiogenic argon -40 quantity can be calculated [18].

New techniques in studying the surfaces of solids have reduced equipment costs. One of these is the ion scattering spectrometer. surface analysis is achieved by using stable isotope ion probes to produce a scan. Helium-3 is one of the ions used in this work [19].

Carbon-13 has long been recognized as a particularly desirable isotope for use in biological and medical research since it is a natural element in living systems and is nonradioactive. Two obstacles to its use in the past have been overcome: its earlier high cost and lack of suitable instrumentation. The large production units have caused a dramatic decrease in price; and improved instrumentation, such 
as nuclear magnetic resonance, has opened the door to a wide scope of studies in life sciences, medicine, organic chemistry, biosynthetic studies, etc. [20]. The availability of labeled compounds has increased considerably, and new syntheses are reported regularly [21]. Since it is nonradioactive, carbon-13 is especially attractive for medical studies involving children and pregnant women. A breath test, in which a carbon-13-labeled compound is administered and respiratory carbon dioxide is recovered and analyzed, shows promise of finding acceptance. Compounds of interest include lactose-1-C, * choly1-glycine-1-C*, trioctanoin-carboxy1$C^{*}$ and aminopyrine for breath test applications to various disorders [22].

\section{Other separation methods}

Mound Facility is studying several other isotope separation methods. Liquid thermal diffusion has been successfully used to separate sulfur-34 at 908 enrichment as carbon disulfide in a 12-column dual cascade on a continuous flow basis [23]. One of the original difficulties was the construction of the concentric cylindrical columns with a uniform annular space. These columns, 0.6 to 2.4 meters long, had a hot-to-cold wall gap of $0.18,0.25$, and $0.30 \mathrm{~mm}$ in contrast to a gap of $3.2 \mathrm{~mm}$ for a concentric tube gas phase thermal diffusion column. Chlorobenzene and 1-chloropropane are being studied for separation of chlorine isotopes by the same method.

Chemical exchange systems for calcium and sulfur isotopes are being developed. The calcium isotope study uses an aqueous calcium chloride solution as one phase and the polyether dicyclohexy 1 18-crown-6 dissolved in chloroform for the organic phase. The sulfur system is based on the sulfur dioxide-sodium bisulfite chemical exchange [23].

\section{Summary}

The separation and use of enriched stable isotopes are expected to continue to increase as development work expands and new applications are developed. Work continues on new instrumentation, medical applications, and environmental problems. Investigations of ecological systems and pollutants may also contribute to the demand for stable isotopes.

\section{Acknowledgements}

The author wishes to thank Dr. Roger A. Schwind, former Manager of the Isotope Separation section at Mound Facility and his staff for helpful suggestions and criticisms. Particular thanks go to Kenneth Foster, one of the original workers on thermal diffusion at Mound, for numerous suggestions and to William Roos for the section on cascade theory.

\section{References}

1. Love, I. O., Science 182, 343 (1973).

2. Keim, C. P., Nucleonics 9, 5 (1951).

3. Clusius, K., and G. Dickel, Naturwissenschaften 26, 546 (1938) and 27, 148 (1939).

4. Smyth, H. D., Atomic Energy for Military Purposes (Princeton University Press, Princeton, New Jersey, 1945) p. 203.

5. Grove, G. R., K. W. Foster, and R. E. Vallee, Proceedings of the Symposium on Isotope Separation, Amsterdam, 1957, 462 .

6. Rutherford, W. M., J. Chem. Phys. 42, 869 (1965). 
7. Rutherford, W. M., and K. J. Kaminski, J. Chem. Phys. 47, 5427 (1967); Roos, W. J., and W. M. Rutherford, J. Chem. Phys. 50, 424 (1969); Rutherford, W. M., W. J. Roos, and K. J. Kaminski, J. Chem. Phys. 50, 5359 (1969); Roos, W. J., and W. M. Rutherford, J. Chem. Phys. 52, 1684 (1970); Rutherford, W. M., J. Chem. Phys. 53, 4329 (1970); Rutherford, W. M. , Sep. \& Purif. Methods, 4, 305 (1975).

8. Rutherford, W. M., F. W. Weyler, and C. F. Eck, Rev. Sci. Instr. 39, 94 (1968).

9. Clusius, K., and H. H. Bühler, Z. Naturforsch A9, 775 (1954).

10. Rutherford, W. M., G. E. Stuber, Jr., and R. A. Schwind, Noble Gases Symposium, Las Vegas, Nevada, Sept. 24-8, 1973, ERDA TIC:CONF-730915.

11. Rutherford, W. M., and J. M. Keller, J. Chem. Phys. 44, 723 (1966): Eck, C. F., Research/Development 24, 32 (1973).

12. Rutherford, W. M., J. Evans, and L. A. Currie, Anal. Chem. 48, 607, (1976).

13. Cowen, J. A., Rev. Sci. Inst. 35, 914 (1964); Radebaugh, R., and J. D. Siegworth, Cryogenics 11, 368 (1971).

14. Eaton, E., and D. Leslie, World Petroleum, 40, 54 (1969).

15. Henault, P. B., E. R. Ebersole, M. T. Laug, R. Villarreal and D. E. Wahler, Trans. Am. Nucl. Socl. 13, 798 (1970); Strand, C. A., and R. E. Schenter, Nucl. Tech. 26, 472 (1975).

16. Blau, M., W. Nagler, and M. A. Bender, J. Nucl. Med. 3, 332 (1962); Tilbury, R. S., J. R. Dahl, J. P. Mamacos and J. S. Laughlin, Inst. J. Appl. Radiat. Isot. 21,277 (1970); Jester,W. A., G. L. Jackson, B. K. Lee, J. S. Burkle, and D. Jarrell, Isot. and Rad. Tech. 9. Summer 1972, 485 (1972); Graham, D., J. of Forensic Sci. 15, 553 (1970).

17. Sydoriak, S. G., J. Res. Nat. Bur. Stand. 68A, 547 (1964); Furukawu, G. T., Metrologia 8, 11 (1972); Baird, K. M., and D. S. Smith, J. Opt. Soc. Am. 52, 507 (1962).

18. Rankama, K., Progress in Isotope Geology, (Interscience Publishers, New York, 1963; Dalrymple, G. B., and M. A. Lamphere, Potassium-Argon Dating (W. H. Freeman and Co., San Francisco, 1969).

19. Karasek, F. W. , Research/Development 24 (1), 25 (1973).

20. Matwiyoff, N. A., and D. G. Ott, Science 181, 1125 (1973); Séquin, U., and A. Ian Scott, Science 186, 101 (1974); Katz, J. J., R. A. Uphaus, H. L. Crespi, M. I. Blake, Isot. Chem. Princ., Symposium, ACS Symp. Ser. 11, 184 (1975).

21. Avona, V. L., and C. F. Eck, Second International Conference on Stable Isotopes, Proceedings, ERDA, oak Brook, I11., 1975, 695; Larsen, S. D., P. J. Vergamini and T.W. Whaley, J. Labelled Cmpd. 11, 325 (1975); Swartz, G. L., and W. M. Gulick, Jr., J. Labelled Cmpd. 11, 525 (1975); Lawson, J. A., W. T. Colwell, J. I. DeGraw, R. H. Peters, R. L. Dehn and M. Tanabe, Synthesis, II, 729 (1975); Hensler, A., P. Ganz, T. Gaeumann, J. Labelled Cmpd. 11, 37 (1975).

22. Klein, P., P. Szcepanik and D. Hachey, Recent Adv. Nucl. Med., Proc. World Congr. Nucl. Med., 1st. 21 (Tokyo, Japan) (1974).

23. Rutherford, W. M., and W. J. Roos, Isotope Ratios as Pollutant Source and Behaviour Indicators, Proceedings, IAEA, Vienna, 1975, 295. 


\section{Distribution}

EXTERNAL

TIC, UC-4 and UC-22 (194)

Monsanto Technical Report Library, St. Louis

E. L. Cussler, Jr., Carnegie-Mellon University

R. K. Flitcraft, Monsanto Research Corporation

W. J. Haubach, DOE/Washington, D. C.

H. N Hill, DOE/Dayton Area Office

N. A. Matwiyoff, Los Alamos Scientific Laboratory

R. E. Meirs, Purdue University

E. Newman, Y-12 Plant

E. Von Halle, $\mathrm{K}-25$

D. White, University of Pennsylvania

R. N. Zare, Stanford University

INTERNAL

W. R. Amos

W. T. Cave

K. W. Foster

C. W. Huntington

J. R. MCClain

E. D. Michaels

W. J. Roos

W. M. Rutherford

G. E. Stuber

R. E. Vallee

W. R. Wilkes

Library (15)

Publications 
$\because$

$+$

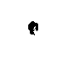


$\because$
$\vdots$

1
1
3

: 